\title{
Response to "Is it Rational to Extrapolate from the Presence of Consciousness during a Flat EEG to Survival of Consciousness After Death?"
}

\section{To the Editor:}

It is my pleasure to respond to Titus Rivas's (2010) letter regarding my recent review of Jeff Long and Paul Perry's book, Evidence of the Afterlife (Holden, 2010). I respect Rivas's commitment to the field of near-death studies and how he uses his intellect in pursuit of that commitment, and I value his many contributions to the field and to this Journal. In my review, I applauded Long on the many contributions his book makes to the field of near-death studies, and I also expressed frustration at two things. One was the limited explanations of methodology that inevitably occur in a book written for the popular rather than professional audience. The other is summarized in these sections from the review:

Of biggest concern is Long's major premise: "[T]he afterlife is for all of us ... a loving . . realm." First, he has generalized to "all of us" an experience that has been reported by a minority of people who survive a close brush with death. Of those survivors, only 10 to 30 percent later report [a near-death experience (NDE)], and 70 to 90 percent have no memory of anything. Also, despite their similarities, every NDE is unique in its contents, which defies a definitive description of "the afterlife." In addition, the nature of consciousness during reversible, temporary death does not necessarily characterize "the afterlife" during irreversible, permanent death. Furthermore, a substantial minority of [near-death experiencers (NDErs)] report distressing rather than "loving" experiences-a topic Long admitted was beyond the scope of his book. (Holden, 2010)

I do agree with Long that much of the data about NDEs lend support to the hypothesis of an afterlife-although commitment to that belief remains, from a purely scientific perspective, a leap of faith. I also believe that the data provide far more equivocal evidence about the exact nature of that existence. (Holden, 2010)

As I was severely constrained by a word limit for the review, I couldn't expand on these points. I'll expand on them in the following 
discussion. I must admit I find it difficult to think in terms of the exact questions that Rivas posed. I hope I will answer his questions through the following discussion.

As I understand it, the process of science is one of creating hypotheses and testing them in light of evidence. One NDE-related hypothesis is that an individual's consciousness-sense of personal identity, perceptual and memory functions, etc.-can function apart from a resuscitatable (reversibly dead) body and brain. My take on the professional NDE literature is that most NDE scholars consider the weight of evidence to support this hypothesis. I join them in that consideration - and I continue to be open to consider evidence to the contrary. The implications of this hypothesis alone are great, but I don't think this hypothesis and its implications are the focus of Rivas's questions.

The hypothesis I believe is in question here is that following irreversible physical death, every individual's consciousness continues to function in the form observed during reversible physical death, that is, during NDEs. In the following discussion, I'll address two parts of this hypothesis: (1) that every individual continues conscious functioning, and (2) that in those who do continue conscious functioning, the functioning takes the form observed in NDEs.

Regarding whether every individual continues conscious functioning, I begin with the matter of incidence of NDEs and the question of the majority of non-near-death experiencers (nonNDErs) among survivors of close brushes with death. Based on results of a recent comprehensive, critical review of all NDE research through 2005 (Zingrone \& Alvarado, 2009), I consider a good round figure of reported NDE incidence in research studies to be $25 \%$. What of the approximately $75 \%$ of nonNDErs who, in both personal characteristics and near-death circumstances, appear equivalent in nearly all ways to NDErs yet report no memory of anything during their close brushes with death? Authors from among the most comprehensive reviews of research comparing NDErs and nonNDErs (Holden, Long, \& MacLurg, 2009; Kelly, Greyson, \& Kelly, 2007) have concluded that factors such as reluctance to disclose NDEs and physiologicallybased memory problems fall far short of accounting for the difference. Some evidence exists that people about to die irreversibly may be more prone to NDEs, but even a confirmation of that finding would not help explain the difference; many people who survive a reversible death episode and soon after die irreversibly don't have NDEs during their survived episodes. 
Some evidence also exists for F. W. H. Myers' "permeable barrier" model whereby some people can more easily traverse the usual barrier between normal and transcendent consciousness. According to this model, "some people have more chronically permeable barriers than others, and in all of us the permeability can vary with changes in physiological or psychological conditions" (Kelly, Greyson, \& Kelly, 2007, p. 414). As Rivas commented in personal communication to me (January 2, 2011), this model is analogous to the EEG discoveries since the 1950s related to sleep. They revealed that everyone REM-dreams for a couple of hours every night but that people's recall of those dreams varies from frequent to none. Analogously, maybe nonNDErs are like dream non-recallers. The problem is that in the case of consciousness during irreversible death, researchers have no equivalent way to test the hypothesis-no way to measure phenomena in irreversible death, neither through something like EEGs nor through subjective reports. Thus, they have no way to confirm that, just as everyone dreams during sleep, everyone remains at least potentially conscious during irreversible death.

Thus, even if further research established NDErs as having more permeability-related characteristics than nonNDErs, how can it be established that the $75 \%$ of people who didn't report ongoing consciousness when they were close to death-even soon-subsequent irreversible death-necessarily experienced it when they finally experienced irreversible death? I consider it possibly, but not necessarily, the case that people chronically non-recalling of transcendent consciousness in life would suddenly begin to consciously experience it in death. Herein lies the fundamental problem of extrapolating to every irreversibly dead person an experience reported by a minority of reversibly dead people: The irreversibly dead have not so far shown up in sufficiently reliable numbers to be studied directly. If they did, I, for one, would especially want to question people who had had multiple NDE opportunities in life but did not have NDEs, to ask them in irreversible death, essentially, "Did you finally experience consciousness akin to what NDErs have described?" Perhaps only a minority of people appear in after-death communication because a majority continue to be as unconscious of (a presumed) transcendent reality in irreversible death as they were in life.

Truly, for all we humans may know, after death some people are not conscious-for some reasons that we may be able to discern and others that "heaven only knows." A possible clue comes from an experience a few years ago in which an acquaintance sought my advice. 
She reported an ongoing distressing experience that she had begun to have a few months previously: communication with her brother who had died from suicide over a decade before. In these communications, she perceived her brother to be quite dazed, confused, and otherwise emotionally distress. She gathered that for most of the time since his death he had been unconscious and had only recently begun to regain consciousness-albeit with no apparent awareness that he was dead and no apparent memory of his suicide. He felt lost and profoundly troubled. Assuming at least the possibility that at least some people some of the time may be unconsciousness, even if such persons can still be said to exist, they don't exist in any way that they-being unconscious-could identify as "an afterlife."

Another possibility is that, as my husband believes will happen to him, upon death at least some people lose all sense of individual identity and memory through dispersion into collective consciousness. As the belief goes, much like the fallen leaf that, in the process of decay, permanently loses its identity as a particular leaf, some irreversibly dead people permanently lose a sense of individual identity as they dissolve into the collective. It is to this process that meditators sometimes report having had anything from a glimpse to an ongoing experience - in the latter case, while they paradoxically maintain a sense of separate self. Actually, I've encountered a couple of cases of NDErs who encountered a kind of border beyond which they would merge into a kind of Ground of Being and, in the process, they believed/ began to experience, would completely and permanently lose their personal/individual identities. These NDErs chose not to proceed, but perhaps some people at death-again, for reasons that "heaven only knows"-instantly proceed into this merger. If so, they may not, upon regaining individual consciousness following resuscitation, have a discernable memory of the experience of loss of individual identity. In this case, as well, even if persons eternally dispersed into the collective can still be said to exist, they wouldn't exist in a way "they"as an individual entity that no longer exists—could identify as "an afterlife."

My point in the foregoing discussion is that, even with access to a large pool of irreversibly dead research subjects, the question of whether every person continues conscious functioning after death would remain a matter of conjecture. NDE data alone cannot provide definitive evidence. Those data certainly narrow the gap in the leap of faith regarding the hypothesis of universal experience of ongoing after-death consciousness: The fact that some people experience 
ongoing consciousness during reversible death certainly suggests the possibility that all people will experience it during irreversible death. But the possibility exists that some people in irreversible death may be unconscious or may transition out of a sense of individual identity that characterizes the typical understanding of "an afterlife" as an ongoing, conscious, individual existence. I believe that physician and researcher Stuart Hameroff was expressing a scientifically appropriate tentativeness about extrapolating beyond "observable" NDE data when, in explaining his microtubule theory of NDEs, he concluded, "By this mechanism, it's possible for consciousness to exist at least temporarily outside the body, for example ... floating above the body, observing the resuscitation" (Broome, 2002; italics added).

I hopefully can make my second main point more briefly. Whether or not everyone experiences ongoing consciousness, regarding those who do, does conscious functioning necessarily continue in the form observed in NDEs? The first problem is that NDEs are so diverse: Despite common deep structure features, each one is unique, with different NDEs containing different features in different forms. Distressing NDErs - those whose experiences were dominated by such emotions as fear, horror, guilt, or isolation-likely would not agree that death represents a universally loving realm. I have heard many NDErs describe encounters or near-encounters with what they perceived as palpable evil. Perhaps even more fundamentally, I've heard NDErs describe their experiences as profoundly plastic - as in the case of Eva who, with an initially amorphous transmaterial "body," wondered if she could touch the distant wall from where her consciousness was located; she instantly "formed" a cartoon-like hand that reached out in a serpentine fashion, touched the wall, then disappeared (Holden, 2008). I have wondered whether at least one factor in the nature of one's after-death consciousness lies predominantly in the consciousness one purposefully cultivates in life and brings along into death. I see no scientific way to predict the exact nature of "the afterlife" from such diverse and plastic phenomena as NDEs.

A second problem is that NDEs are typically so limited; this limitation brings me to the Then what? question. A person goes through a tunnel, meets and communicates with deceased loved ones and/or spiritual entities, enters the Light and has a life review-and if the person remains dead, then what? Does the person meet and communicate in the same fashion with more transmaterial entities, have more life review, or what? What exactly does one "do" and/or "experience" for all eternity—or at least until the next incarnation? Germaine to 
this second question is a phenomenon many NDErs have reported: a barrier beyond which they-their consciousnesses-would be so transformed as to render them incapable of reinhabiting their physical bodies. Again, barring a cooperative sample of irreversibly dead people who have been through this barrier (and still can communicate with us?), we humans cannot know the nature of that apparently fundamental transformation - and how consciousness might function differently once it occurs. Between the diversity, plasticity, and limitations of NDEs, as far as I can see, using NDEs to extrapolate about the exact nature of the afterlife is beyond the domain of science; thus, using them alone, the nature of "the [post-NDE] afterlife" will continue to remain predominantly a mystery.

In summary, to respond directly to Rivas's title question, I consider the extrapolation from the presence of consciousness during a flat EEG to the universal survival of individual consciousness after death to be a rational, calculated leap-with rationally defensible alternative possible extrapolations. In Rivas's conclusion, he referred to moving beyond NDE evidence alone and using a convergence of evidence from a variety of transpersonal phenomena to clarify the questions of who experiences after-death consciousness and what is the nature of that consciousness. I concur heartily and have seen increasing publications of this kind (Kelly, Kelly, Crabtree, Gauld, Grosso, \& Greyson, 2007; see also Gibbs, 2010 [this issue]).

Though I have never actually met Rivas, I thank him for his questions, hope I have answered them, and look forward to the time when, I believe, he and I will meet in afterlife as friends.

\section{References}

Broome, K. (Producer). (2002). The day I died: The mind, the brain, and neardeath experiences [videorecording]. London, England: British Broadcasting Corporation. Available at http://www.films.com/id/11685.

Gibbs, J. C. (2010). Near-death experiences, deathbed visions, and past-life memories: A convergence in support of van Lommel's Consciousness Beyond Life. Journal of Near-Death Studies, 29(2), 303-341.

Holden, J. M. (2008). Near-death experiences, part 1: Recognizing a pleasurable near-death experience [online continuing education program]. Durham, NC: International Association for Near-Death Studies. Available at http://www. iands.org/education/educational_credits/ceu-course-home.html.

Holden, J. M. (2010, August). Book review: Evidence of the Afterlife: The Science of Near-Death Experiences. Noetic Now, 1. Petaluma, CA: Institute of Noetic Sciences. Available at http://www.noetic.org/noetic/noetic-now-issue-one-may/ review/. 
Holden, J. M., Long, J., \& MacLurg, B. J. (2009). Characteristics of near-death experiencers. In J. M. Holden, B. Greyson, \& D. James (Eds.), The handbook of near-death experiences: Thirty years of investigation (pp. 109-134). Santa Barbara, CA: Praeger/ABC-CLIO.

Kelly, E. F., Kelly, E. W., Crabtree, A., Gauld, A., Grosso, M., \& Greyson, B. Irreducible mind: Toward a psychology for the 21st century. Lanham, MD: Rowman \& Littlefield.

Kelly, E. W., Greyson, B., \& Kelly, E. F. (2007). Unusual experiences near death and related phenomena. In E. F. Kelly, E. W. Kelly, A. Crabtree, A. Gauld, M. Grosso, \& B. Greyson, Irreducible mind: Toward a psychology for the 21st century (pp. 367-421). Lanham, MD: Rowman \& Littlefield.

Rivas, T. (2010). Is it rational to extrapolate from the presence of consciousness during a flat EEG to survival of consciousness after death? Journal of NearDeath Studies, 29(2), 355-360.

Zingrone, N. L., \& Alvarado, C. S. (2009). Pleasurable Western adult near-death experiences: Features, circumstances, and incidence. In J. M. Holden, B. Greyson, \& D. James (Eds.), The handbook of near-death experiences: Thirty years of investigation (pp. 17-40). Santa Barbara, CA: Praeger/ABC-CLIO.

Janice Miner Holden, Ed.D., LPC-S, LMFT, NCC Department of Counseling and Higher Education

University of North Texas

1155 Union Circle \#310829

Denton, TX 76203-5017

jan.holden@unt.edu 